\title{
- Review Papers
}

\section{Nursing Strategies for Reducing Medication Errors}

ImanAbdallah Mohammed Abdulmutalib, Amany Mohammed Safwat

Medical-Surgical Nursing Department, Nursing Faculty, Ain Shams University, Egypt

\begin{abstract}
Medication errors in hospitals remain one of the most common causes of unintentional harm to patients and are a major cause of errors that disrupt the health care system. It contributes to adverse events that threaten patient safety and lead to a significant financial burden on the health service. Prevention of medication errors occurs at every stage of the drug preparation and distribution process, which is necessary to maintain a safe health care system. One-third of errors that harm patients occur during the nurses' management phase administration of the drug to patients is a very dangerous activity.Nursing is responsible for the medication management phase, which includes monitoring the effectiveness and adverse effects, and therefore, the professional nurse is likely to reveal the fault of the medication, as it is one of the major responsibility to examine the medication before giving it to the patient. Nurses are the last line of defense to prevent medication error and catch up with medication errors before they occur.This article describes factors that contribute to medication errors, and also addresses factors that specifically relate to nurses, such as patient severity classification and nursing workload, deviations and interruptions that may occur while taking medication, the complexity of certain calculations and medications, nurses' failure to comply with policies or Guidelines. Many of the strategies proposed to reduce medication errors include
\end{abstract}


increasing the number of nursing personnel and adjusting their workload, effective management, increasing nurses' knowledge of drug management and encouraging nurses to report medication errors to prevent them and enhance patient safety.

Keywords: Medication administrations errors, contributing factors, Causes, Reducing nursing strategies

\section{Introduction}

Medication error is an unintentional failure in the medication process that leads to or has the potential to harm the patient. Reducing the risk of medication errors is a shared responsibility among patients, healthcare providers, managers and the pharmaceutical industry at all levels of health care delivery [1].

A medication error is a universal problem within the health field. The preventable medication error is the biggest cause of mortality and morbidity in the health care environment [2]. Medication errors are one of the accidents, affecting the safety of patients, more than 7,000 deaths per year [3].

Furthermore, "Institute of Medicine" reported that around 98,000 deaths occur yearly due to medication errors [4]. One of the significant impacts of medication errors is the cost, so the health care setting spends $\$ 32.59-\$ 136.40$ for patients' hospitalization [5]. A predictable $1 \%$ to $2 \%$ of the medication errors result in patient injury. The result of the injury contributes to an increased hospital stay between 4.6 to 10.3 days for every affected patient [6].

Medication administration is one of the stages provided by nurses, who consumed around $16 \%$ of working hours dispensing or administering medication [7]. High rates of drug administration, as well as other duty loads, increase the number of nurses at risk of medication error. An educated nurse will take care of the individual human mistakes that they may control themselves. So, is this an important step for other healthcare professionals such as a doctor and pharmacist in all areas of health care facilities? [8].

Safety is a concern for healthcare providers worldwide. "The mission of the National Coordinating Board for Drug Error Reporting and Prevention is to maximize the safe use of medicines and increase awareness of medication errors 
through open communication, increased reporting and promotion of medication error and prevention strategies. Identifying contributing factors and reducing strategies regarding medication administration errors, an attempt to reduce the rate of errors.Moreover, an introduction to these errors is important in educating nurses about what they will experience in a health care facility [9].

\section{Definition and Classification of Medication Errors}

"The National Coordinating Council for Medication Errors Reporting and Prevention defined a medication error as any preventable event that may cause or lead to inappropriate medication use or patient harm while the medication is in the control of the health care professional, patient, or consumer. Such events may be related to professional practice, healthcare products, procedures, and systems, including prescribing, order communication, product labeling, packaging, and nomenclature, compounding, dispensing, distribution, administration, education, monitoring, and use" [9]

"The European Medicines Agency defines a medication error as an unintended failure in the drug treatment process that leads to or has the potential to harm patients. Mistakes in the prescribing, dispensing, storing, preparation and administration of medicine are the most common preventable cause of undesired adverse events in medication practice and present a major public health burden" [10].

To facilitate compliance with pharmacovigilance obligations and to encourage reporting of patients and health care workers for regulatory purposes, a new definition of medication error is proposed as "unintentional failure in the process of drug therapy leading to or causing harm to the patient." With this definition, failure is interpreted as an error, facilitated by human or process rather than ineffective medication, and for the purposes of recording and reporting caution from pharmacovigilance, concepts of intended overdose and off-label use, abuse, and abuse need to clearly distinguish from medication errors [1].

In the classification proposed in Figure 1, it can be observed that the medication error may be associated with an adverse drug reaction or may occur without damaging the patient. Moreover, an error may occur but is intercepted before it reaches the patient. The classification includes recognition of conditions that 
may lead to a medication error and may or may not include the patient as a possible error [11].

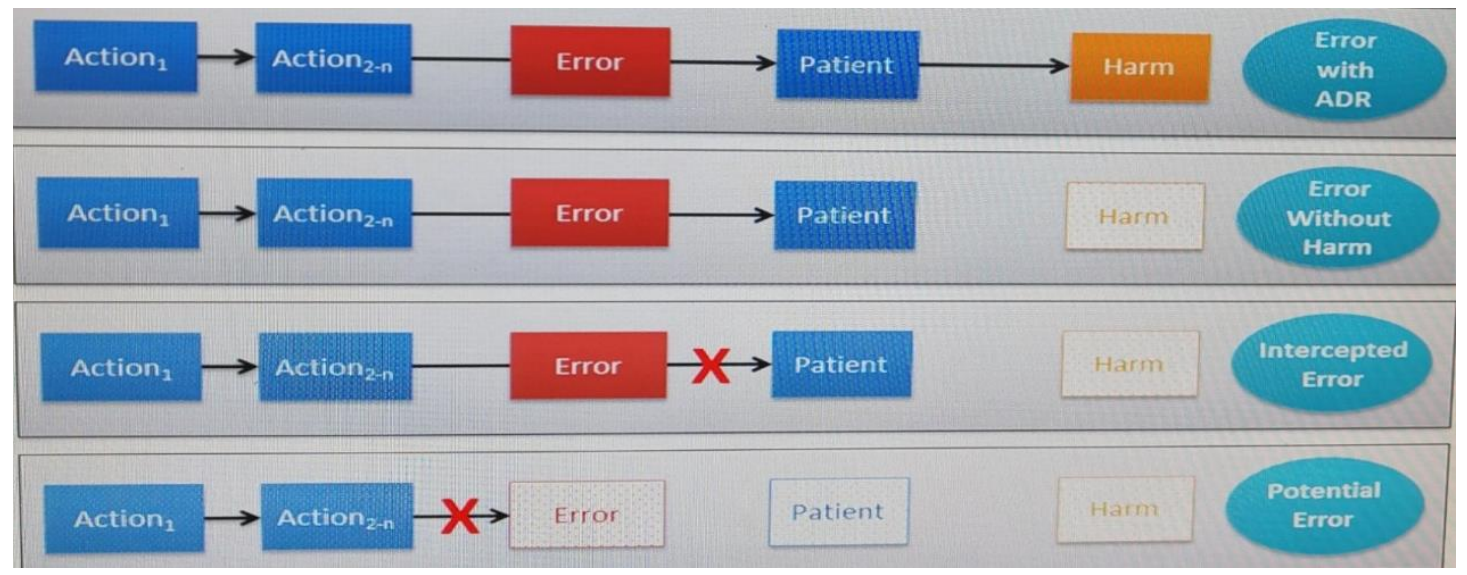

Figure 1: Classification of medication error reports for pharmacovigilance purposes. Depending on the fracture of the chain of events (represented by $\mathrm{X}$ ), the errors of the drug may be classified as an error with an adverse drug reaction, an error without damage, an intercepted error and a possible error Adverse drug reaction. (Pharmacovigilance Risk Assessment Committee. Good practice guide on recording, coding, reporting, and assessment of medication errors [11].

\section{Types of Errors:}

\section{Active errors}

The active errors result from an individual's failure e.g. in related to medication errors: miscalculation of the drug, errors in pharmaceutical equipment or improperly prepared (for example, intravenous pump), nurses do not follow the policy and procedures of medication administration, the pharmacy provides an incorrect drug and unread handwriting for medication orders [12]. 


\section{Latent Errors}

Latent errors result from organizational system failures that will allow active errors to happen and cause patient harm, for example about medication errors, nurses do not have adequate education for new drugs, as some drugs are similar and sound-like, an insufficient place to prepare the drug and workload[12].

\section{Medication Errors Prevalence, Incidence and Cost}

Medications are used to treat many diseases, on another hand may cause unintended incident "adverse drug reaction" and "adverse drug events". "Medication errors are among the most common medical errors, harming at least 1.5 million people every year, the extra medical costs of treating drugrelated injuries occurring in hospitals alone are at least to $\$ 3.5$ billion a year"." [13].

A study conducted in 20 hospital wards in Iran, direct observation method was chosen for identifying the errors, 8000 medication doses were studied in a different stage (prescribing, transcribing and administering). Reported that the $73 \%$ prescribing errors related to incomplete parameters (name of patients, dosage, and unit of medication, route, and time of administration), $15 \%$ related to transcribing errors, one-third of errors in the administration medications and $1.4 \%$ to $2.2 \%$ dispensing errors [14].

There were 54 studies from 10 Middle Eastern countries. Found that the error incidents different from stage to stage, prescribing up to $90.5 \%$ and administration up to $80 \%$. The major errors that occur in the prescribing stage were inappropriate dose, wrong frequency, and wrong strength. [15].

The medication safety is a major part of the patient's quality care and safety. In a way to develop the basics safety related to medication in a health care setting, a systematical review of medication errors in different databases, the studies were chosen from 2001 to 2011. Found that the medication errors were related to nursing are competency, nursing process, prescription and patient factors, and safety culture. For this purpose, in 2002, "The Joint Commission established its National Patient Safety Goals (NPSGs) program to help 
accredited organizations address specific areas of concern regarding patient safety" [16, 17].

\section{Medication Process}

The application of the medication process (prescriptions, dispensing and administration) needs the cooperation of various health care providers by doctors, then pharmacists and ends with nurses [18]. Medication errors occur at any stage of the medication process. The prescription, as well as the administration, imposes the highest rate of all errors by rounding $39 \%$ and $38 \%$ respectively [19].

The quantify and characterize the medication errors incidents at surgical intensive care unit (SICU), conducted an one-month prospective observational study to detect, quantify and score medication errors in a SICU, found a total of 634 observations made over weekdays and weekends were performed including morning, noon and night shifts, a 245 medication errors were reported. According to the type of errors found: 52 were prescription errors, 44 related to administration technique, 10 omissions of the administration record, 97 erroneous preparations, 1 wrongly prescribed dose by default and 3 by excess, 5 errors related to erroneous administration route, 2 erroneous drug monetarization and 29 transcription errors [20].

\section{1- Physician Ordering and Prescribing Stage}

"An order for medication, therapy, or therapeutic device is given by a properly authorized person, who ultimately goes to a person properly authorized to dispense or perform the order. A prescription is usually in form of; electronic order, written, phoned; and includes the patient's name, the date, the medication prescribed, route, and frequency, directions to the pharmacist or another dispenser, then directions to the patient. Prescriber's signature needed, and in some instances, an identifying number [21].

A prescription is printed of the patient's medication on the chart by a physician or by a nurse who receives a telephone or verbal order. The essential parts of a medication order are the full name of the patient, date and time, name of medication, dosage, frequency, route, and signature of the person writing the order [22]. The prescription 
errors can involve prescribing the wrong medication for a patient or prescribing the wrong dose and/or quantity of the medication. It may be that several medications are prescribed for the patient and there is an interaction between the medications, or the patient has a known allergy to the medication- these are classed as adverse drug reactions [23].

The most common cause of prescribing errors related to the use of abbreviations and poor handwriting. There are several good practice principle that should be followed when prescribing medications adopted by this commission: using of plain English, write in full no abbreviations, print all text especially medication name, use generic medication name, don't use chemical symbols, use word or numbers, use metric units, use a leading zero in front of decimal point and don't use fractions, other countries have similar guidelines [24].

\section{2- Pharmacists Dispensing and Delivery Stage}

"The preparation, packaging, labeling, record keeping, and transfer of a prescription drug to a patient or an intermediary who is responsible for the administration of the drug [21]. Dispensing errors occur when the medications dispensed differs from the medication prescribed. This results when the order is misinterpreted either in the term of the medication itself, the dose or quantity. Other errors that can occur in the dispensing are if the label is generated incorrectly and/or affixed to the wrong package or container. The final process of dispensing where there is a possibility of errors related to ensuring that the prescription is given to the correct patient [23].

\section{3- Nurses Administering Stage}

Medication administration processed by nurses, follow the following steps: first, identify the correct patient by using a wristband, and the questioning awake patient to say the name or verify hospital medical number. Second, nurses inform the patient about medication and possible side effects. The third, before administering medication check the drug name, order, dosage, expiry date and double-check with another nurse. Fourth, provide some intervention need to prevent side effects or increase medication effectively e.g. increase fluid 
intake or drug need to administer on an empty stomach. The fifth step document medication administration and all information related to drug and patient feedback. Nurses are responsible for having an action to incorrect or unclear medications order before administrations [22].

An administration error occurs when any one of medication administration rights is breached. The administration of medication is where the majority of errors occur, as multiple steps in this process can go wrong. Wrong dose, dose omission, and wrong administration time are the most common administration errors types. As with dispensing errors, frequent causes of administration errors are ordered in which the medication name, dose, or route are illegible, although misheard verbal orders and transcription mistakes of medication orders can also lead to errors [23].

\section{Contributing Factors regarding MAEs}

Adoption of error-prone abbreviations to prescribe medication is the contributing factor of misinterpretation resulting in a medication error. The error-prone abbreviations inpatient drug prescribing is common. Data collected across three Australian hospitals found that about $76.9 \%$ of patients were experiencing a series of error-prone abbreviations that were being utilized in specifying. Only $8.4 \%$ of orders had one error-prone abbreviation and $29.6 \%$ had a high probability of causing significant harm [25].

The popular types of medication errors among 237 nurses were infusion and wrong dosage. However, the paramount causes attribute to using abbreviations rather than using all names of the drugs or related names of drugs. Therefore, inadequate pharmacological knowledge was the primary cause of medication errors [26].

Medications packaging, handling, storage, and delivery system are important considerations for medication safety. Medication packaging that is similar increases the chances of error and storing medication with similar packing and/or similar names close to each other can lead to inadvertent mix-ups when the busy nurse, pharmacist or physician is reaching for a particular medication [23]. 
Some of the factors are nurse's tiredness because of much work, doctors' indecipherable handwriting, and interruption while administering drugs [27]. The medication administration includes complex process; thus it follows that anyone taking part in the process is distracted or interrupted is more likely to make mistakes. An e.g. of this might be when the nurse starts to get organized to give a patient their morning insulin and interrupted by another request from the patient which occupies some time. Then go on to deal with other tasks and only realize the insulin has not given when the patient experiences hyperglycemia [23].

The nursing practice manifold majorly causes the factors attributing to medication errors, back from 1988 to 2007 and they are related to individual and systems factors. They include reconciliation, too much workload, the nature of prescriptions, nurses' knowledge about drugs and implementing other policies, procedures, and distractions during the administration [28].

Human factors model to conceptualized workload and found that workloads may affect health care providers and patient outcomes. The nurse's workload affects the practice, patient safety, outcome, and quality [29].

Categorized factors contributing to medication errors to, first individual factors included: forgetfulness, inadequate knowledge, communication errors, drug abuse, not follows the policy and procedure, the second categories about organization factors which included: similarities of medications, lack of guidelines, overload interruption/distractions and pressure by work, collages and patients [30].

In addition to medication errors contributing factors; some factors related to environment were heavy workload, rapidly changes situations (acute care, emergency situations, frequent changes of orders and care plans, high number of admission and discharges), staff shortage and staff working in unfamiliar clinical contexts all lead to situations in which clinicians are frequently interrupted and subject to multiple distractions [23].

Lessened capacity for work, reduced efficiency, and feeling of tiredness may affect patient care. Fatigued nurses were three times more likely to make serious mistakes when attending patients [31]. 


\section{Reducing Strategies Regarding MAEs}

The literature reported different reducing strategies of medication errors that health care providers should apply to practice for improving patient's safety. Continuing education sessions at some of the nation's largest healthcare professional meetings. Topics range from prevention of medication errors in specialty settings to error-prevention strategies for drug naming, labels, and packaging, as well as the use of automation and electronic prescribing to reduce error risk"[32].

The key to implementing a successful intervention that minimizes medication management errors is understanding how and why it occurs. Since nurses find themselves "the last link in the chain of drug therapy" where the error can reach the patient, they have traditionally been blamed for errors [32]. However, the reality is that the circumstances in which the person responsible for the error, as well as the strategic decisions of the organization with which they work, are often the main determinants of error. Frameworks for the analysis of medical errors have been developed as well as the categories of recording medication errors that recognize this distinction [34, 35].

To determine the cause of the error, one must appreciate the intentions of the person responsible for it. To achieve this, one might ask directly, but care must be taken because the drug administration error data generated in this way can be based on public opinion in nursing rather than on specific error trials, which may not reveal the true complexity of how individual drug administration errors appear. Another way is to observe the causes that cause errors when they occur without referring directly to the person concerned by mistake, while avoiding the researcher's opinion on the causal relationship. Direct observation is the best available method for determining the prevalence of drug administration errors and may identify potential causes of error and associated factors, which may not be observed by the person who makes the error or may not reveal recovery methods retroactively [36]

\section{The Strategies}

Can include computer-based entry systems medication-error analysis, programmed dispensing cabinets, bar-coding systems. The nurses can also adopt 
systematizing medication usage, medication reconciliation, education and training, and clinical pharmacists [37].

\section{1- Orientation about Medication Administration Policies and Procedure}

To ensure the consistent and correct use of medications a permanent chart record available which documents all medications given called policy and procedure [38]. So, the purpose of the policy and procedure is to detail "best practice" in the administration, storage, ordering, receipt and the return of medication [39].

\section{2- Reconciliation}

Different health care specializes provide strategies that can reduce medication errors example (e.g.) pharmacists. "Medicinal conciliation (MR) can be defined as the formal process of examining the complete and accurate list of pre-patient medications and comparing them with prescriptions after the transition of care and at discharge [40].

The Irish government was the first to use medication reconciliation at the transfer of care. Clinical pharmacists did the trial phase among patients that were selected randomly within 24-hours of admission used a pre-admission medication list and communicating any changes. In the end, $50 \%$ of interventions were accepted and discrepancies resolved [41]. The conflict during admitting and discharging of patients' the process of medications could contribute to adverse drug issues. Patients are prone to gaps in medication during the moment experiencing the transition of care or sometimes discharge. The integration of the pharmacist reviewing process during medication reconciliation at discharge identifies and corrects conflicts [42].

\section{3- Training and Safe Practice}

A vital link in the prevention of medication errors is educating all health care professionals who involved in the medication process. Understanding the contributing factors that may increase the likelihood of medication errors is important. If everyone in the healthcare continuum needs education, then there will be greater chances of reducing the error [32]. 


\section{4- Double Check Procedure}

The successful implementation of double-check procedures by a second person to observe the person who preparing medication and report what is supposed to observe regarding safe medication administration, even if an error has happened. Two people are required to check each component of the work process [43].

The effectiveness of using double-check technique, the findings recorded that there were reductions in medication administration errors by using doublecheck technique [15]. Besides, the protocol that calls for double-checking of medication administration rights during dispensing and administration is another strategy for minimizing the risk of errors [23].

\section{5- Staffing (Patient-Nurse Ratio) and Working Hours}

There is a continuous rise in the prevalence of medication error, which calls for the attention of nursing leaders to act in the mitigation of the problem. To understand the association between nurse staff and medication error occurrence, a retrospective study design used to analyze data from secondary sources such as administrative databases of a hospital. The study indicated that an increase in the proportion of $\mathrm{RN}$ hours and a decrease in the proportion of Licensed Practice Nurse hours, a strategy could effectively reduce the problem of medication errors [44].

As much as insufficiency in nursing staff has an impact on patient care, having competent nurses can reduce the level of errors in inpatient care. A survey of approximately 500 nursing staff in 3 hospitals found $85 \%$ of missed cases were a result of a few labor resources (Licensed practice nurse). Nevertheless, the study pointed that with a limitation of the nursing staff to meet the patient's needs, there is a high probability that they will omit steps, deviate from approved standards, and take short cuts to get the work done, which would ultimately compromise the quality of care [45].

Although observation medication administration to identify the factors that affecting medication safety, found that in most cases where nurses omitted some 
medication five rights and unsuccessful to follow the medication administration policy and procedure, contribute to a high likelihood of medication error. Nevertheless, to facilitate the observation of the five rights of medication, hospitals must be adequately staffed to ensure the nurses are not overworked, which might force them to seek short cuts [46].

\section{6- Rights Rule of Medication Administration}

It is the nurses' responsibility to ensure the safety and quality of patient care. Most of the patients harmed by a medication error, with some of these patients suffering permanent disabilities while the unlucky ones succumb to death. The right patient, route, drug, dose and time are the 5 rights of medication administration that nurses have traditionally followed for decades. Nevertheless, to increase efficiency, documentation and reason have been added making the seven rights of medication administration. Scholars have suggested the inclusion of Right Action, Right form, and Right response to even further the safety of the patients [47].

Other scholars have argued that ten rights of medication administration should be observed. These rights include Rights drug, patient, dose, route, time and frequency, documentation, history, and assessment, right to refuse, right drug-drug interaction and evaluation and right education and information [48].

\section{7- Distraction/ Interruption during Medication Administration}

The incidence and frequency of interruption were significantly related to a failure to the procedure and medication error. In this regard, avoidance of distraction during medication is important for the safety of the medication [49].

\section{8- Computerized Prescriber Order, Automated Medication Dispensing and Barcode Medication Administration}

Barcoding has a significant effect on the reduction of medication error incidents. The application of barcode verification and scanning technology and ascertained the usefulness of barcode in the elimination of medication error [50]. Additionally, [51] conducted reviews and appraisals and found compelling 
evidence among the seven controlled trials (CTs) and six Randomized controlled trials (RCTs) of the effectiveness of barcoding in the management of medication error.

The bar-code verification works in a manner that the nursing staff scans the code on the patients' identification band, which contains a unique patient's identifiers. This action leads to the appearance of the patient's prescribed medical information appearing on the screen. This is followed by scanning the medication bar code which would expose information such as the medication's name, dose and other specific information that may be contained in the bar code and ensure they match with the patient's order. The bar-code verification could decrease but no elimination of patient identification and medication error in a medication administration [52].

As much as a variety of options have been put in place to improve medication safety in prescribing, dispensing, transcribing and administering, more needs to be done, propose a focus on medication reconciliation, computerized physician order entry, bar code, automated medication dispensing and smart pumps [53].

\section{9- Clinical Pharmacist}

The clinical pharmacist is another strategy to reduce medication error. The clinical pharmacist should participate during ward round to optimize the planning and implementation of quality care through quality drug administration [54]. On the other hand, the significance of clinical pharmacist role in the emergency department through identification, and assessment of the many different interventions made by the pharmacist with the interdisciplinary team [55].

The clinical pharmacists have a significant effect on decreasing the medication error. The clinical pharmacists detected different categories of medication errors as opposed to those detected by different healthcare providers. This thus implies that clinical pharmacists have an integral role in the prevention of medication error and thus are important members of the interdisciplinary team [56]. 


\section{0- Communication between Health Care Provider (Physician, Nurses, and Pharmacists)}

Communication between Physicians, Nurses, and Pharmacists directly increases the patients' safety, improves the healthcare practice, and decreases the likelihood of medication error. The focus was to understand the knowledge approach to developing an understanding of problems in communication to constructing an evidence-based tool that can be applied to eliminate miscommunication issues in the health care setting [57].

Effective communication is critical during the numerous interactions that occur among health care professionals daily. Health care professionals must know how to communicate effectively at work and collaborate with teams to ensure that appropriate information is shared inappropriate time. In the absence of effective communication, patient care is compromised, hence many scholars have cited communication breakdown as the primary cause in almost every case of patient neglect [58].

Multiple studies surveyed nurses looking for the causes and types of medication errors, and the results vary widely. Among the causes of medication errors identified by nurses are (1) careless failure to follow the five rights, (2) nursing incompetence, (3) distractions, (4) interruptions, (5) inadequate staff, (6) unread written orders, (7) incorrect dosage calculations, (8) medication names and similar packaging, (9) non-verification of the scope of the name with the drug administration record, and (10) failure to follow policies and procedures [59]. Respect for authority as a cause of medication errors. For example, during the second checks of high-risk drugs, new nurses are reluctant to say that the drug designed by an experienced nurse is incorrect.

Six studies observing direct administration of medication by ICU nurses identified the wrong dose, wrong administration time, wrong administration rate, and dose omission as the most common types of medication errors [60].

\section{Nursing Strategy List to Decrease Interruptions during Medication Administration [61].}


- Nurses will wear brightly colored sashes during medication administration.

- Nurses will retire personal staff phones during the duration of medication administration.

- Nurses will place a colored dot next to their name on the board posted at the nurse's station when passing medication.

- Nurses will use a checklist for each patient when pulling medications to keep track of which medications have and haven't been pulled

- Nurses will ask patients and family members to express any questions or concerns before medication administration begins

- Nurses will use a verification booth before entering the patient's room to check the medications with the electronic and paper orders

- Nurses will say each medication name out loud when pulling and administering medications

- The area surrounding a patient's IV pole will be considered a "no interruption zone" when the nurse is hanging IV fluids and medications and when programming pumps.

- A visual timer will be attached to IV poles to be used when nurses administer IV push medications

- Nurses will use both the electronic and paper list of their patient's medications to verify orders before administration

In summary, damage to patients due to medication errors has not been reduced in the past 15 years, despite considerable efforts to the contrary. The nursing profession has the potential to play a key role in reducing error. However, the role of the nurse in reducing medication errors remains elusive. We know that nurses make mistakes in medicine due to a lack of knowledge, calculation skills, and performance, but research efforts directed at these problem areas have not affected any change [62, 63]

Conclusion: To minimize the incidence of medication errors, it is significant to develop policies to combat the hazard of medication errors in all steps of the medication process. Institutions should develop cultures that promote the reporting and correction of these errors in a systematic and unfavorable manner. There are multiple strategies for reducing and mitigating these errors, including 
medication error analysis, automated dispensing tanks, bar-coding systems, medication reconciliation, standardization of medicationprocesses, education, and clinical pharmacists in emergency medicine.

Conflict of interest: There is no conflict of interest.

\section{References:}

[1] Goedecke, T., Ord, K., Newbould, V., Brosch, S., \&Arlett, P. (2016). Medication errors: new EU good practice guide on risk minimization and error prevention. Drug safety, 39(6), 491-500.

[2] Cousins DH, Gerrett D, Warner B. (2010). A review of medication incidents reported to the National Reporting and Learning System in England and Wales over 6 years (2005-2010). Br J ClinPharmacol. 2012; 74(4):597-604.

[3] Flynn, L., Liang, Y., Dickson, G. L., Xie, M., \&Suh, D.-C. (2012). Nurses' practice environments, error interception practices, and inpatient medication errors. Journal of Nursing Scholarship: An Official Publication of Sigma Theta Tau International Honor Society of Nursing / Sigma Theta Tau, 44(2), 180-6.

[4] James, J. T. (2013). A new, evidence-based estimate of patient harms associated with hospital care. Journal of Patient Safety, 9(3), 122-8.

[5]Samp, J. C., Touchette, D. R., Marinac, J. S., \&Kuo, G. M. (2014). Economic evaluation of the impact of medication errors reported by u.s. clinical pharmacists. Pharmacotherapy, 34(4), 350-357. http://doi.org/10.1002/phar.1370

[6] National Quality Measures Clearinghouse (NQMC). (2013). Agency for Healthcare Research and Quality, Rockville, MD. Retrieved from http://www.ahrq.gov/cpi/about/otherwebsites/qualitymeasures.ahrq.gov/index.html.

[7] Garrett, R. and Craig, J. (2009) Medication Administration and the Complexity of Nursing Workflow. Paper presented to the Proceedings of the Institute of Industrial Engineers Society of Health Systems Conference, Chicago.

[8] Sears, K., O’Brien-Pallas, L., Stevens, B. and Murphy, G. (2013). The relationship between the nursing work environment and the occurrence of reported medication administration errors: a pan Canadian Study. Journal of Pediatric Nursing.Vol. 28. No. 4. pp 351-356.

[9]Medication errors definition. National Coordinating Council for Medication Error Reporting and Prevention (2016). Retrieved from http://www.nccmerp.org/aboutmedication-errors.-

[10]Medication errors. European Medicines Agency (EMA), (2016) retrieved fromhttp://www.ema.europa.eu/ema/index.jsp?curl=pages/special_topics/general/gener al_content_00 0570.jsp. 
[11] Pharmacovigilance Risk Assessment Committee. Good practice guide on recording, coding, reporting and assessment of medication errors (EMA/762563/2014). 2015. Available http://www.ema.europa.eu/docs/en_GB/document_library/Regulatory_and_procedural _guideline/2015/11/WC500196979.pdf. Accessed 27 Nov 2015

[12] Collins, S. J., Newhouse, R., Porter, J., \&Talsma, A. (2014). Effectiveness of the surgical safety checklist in correcting errors: A literature review applying reason's Swiss cheese model. AORN Journal, 100(1), 65-79.e5.

[13]Aspeden, P., Wolcott, J., Bootman, J., \&Cronenwett, L. (eds.) (2007). Preventing Medication Errors: Quality Chasm Series. Washington, DC: Institute of Medicine [14] Saghafi, \& F, Z. A. (2014). Saghafi F, Zargarzadeh AH. Medication error detection in two major teaching hospitals: What are the types of errors? Journal of Research in Medical Sciences: The Official Journal of Isfahan University of Medical Sciences, 19(7), 617-623.

[15] Alsulami, Z., Conroy, S., \&Choonara, I. (2013). Medication errors in the Middle East countries: A systematic review of the literature. European Journal of Clinical Pharmacology, 69(4), 995-1008.

[16] The Joint Commission (2015) Facts about the National Patient Safety Goals retrieved https://www.jointcommission.org/facts_about_the_national_patient_safety_goals/.

[17] Metsälä, E., \&Vaherkoski, U. (2014). Medication errors in elderly acute care - a systematic review. Scandinavian Journal of Caring Sciences, 28(1), 12-28.

[18] Karavasiliadou, S., \&Athanasakis, E. (2014). An inside look into the factors contributing to medication errors in the clinical nursing practice. 8

[19] National Quality Measures Clearinghouse (NQMC). (2013). Agency for Healthcare

Research and Quality, Rockville, MD.Retrived from http://www.ahrq.gov/cpi/about/otherwebsites/qualitymeasures.ahrq.gov/index.html. [20] Cuesta-Montero, P., Domingo-Chiva, E., Plata-Paniagua, S., Monsalve- Naharro, J., Montalban-Moreno, B., Jimenez-Vizuete, J., Peyro-García, R. (2015). Incidence of Medication Errors in a Surgical Intensive Care Unit.Analisys and Improvement Measures Implemented.Intensive Care Medicine Experimental, 3(Suppl 1), A75.

[21] Drug dispensing. (n.d.) Mosby's Medical Dictionary, 8th edition. (2009). Retrieved May 2016 from http://medicaldictionary.thefreedictionary.com/drug+dispensing.

[22] Berman, A., Snyder, S. J., Kozier, B., Erb, G. L., Levett-Jones, T., Dwyer, T., \& Parker, B. (2014). Kozier\&Erb's Fundamentals of Nursing Australian Edition (Vol. 3). Pearson Higher Education AU.

[23] Heather Gluyas Paul Morrison. (2013) Patient Safety: An Essential Guide: Medication Errors, 1137316322, 9781137316325.

[24] ACSQH. (2012). Safety and Quality Improvement Guide: Medication Safety. 
Bae S.H. (2011). Assessing the relationships between nurse working conditions and patient outcomes: systematic literature review. Journal of Nursing Management 19, $700-713$.

[25] Dooley, M. J., Wiseman, M., \&Gu, G. (2012). Prevalence of error-prone abbreviations used in medication prescribing for hospitalized patients: multi-hospital evaluation. Internal Medicine Journal, 42(3), e19-22.

[26] Cheragi, M. A., Manoocheri, H., Mohammadnejad, E., \&Ehsani, S. R. (2013). Types and causes of medication errors from nurse's viewpoint. Iranian Journal of Nursing and Midwifery Research, 18(3), 228-31.

[27]Elmira Petrova. (2010). Nurses' perceptions of medication errors. International Journal of Clinical Pharmacology Research, 22(3-4), 111-116.

[28] Brady, A. M., Malone, A. M., \& Fleming, S. (2009). A literature review of the individual and systems factors that contribute to medication errors in nursing practice. Journal of Nursing Management, 17(6), 679-697.

[29] Holden, R. J., Scanlon, M. C., Patel, N. R., Kaushal, R., Escoto, K. H., Brown, R. L., Karsh, B.-T. (2011). A human factors framework and study of the effect of nursing workload on patient safety and employee quality of working life. BMJ Quality \& Safety, 20(1), 15-24.

[30] Bergqvist, M., Karlsson, E. A., Björkstén, K. S., \&Ulfvarson, J. (2012). Medication Errors by Nurses in Sweden-Classification and Contributing factors, 1(11), $1-4$.

[31] Lewandowski, C. M. (2010). Theimpact ofFatigue on Medicationerrors By Registered Nurses. The Effects of Brief Mindfulness Intervention on Acute Pain Experience: An Examination of Individual Difference, 1.

[32] Institute for Safe Medication Practice (ISMP). (2016). Educational Programs, Retrievedfrom http://www.ismp.org/educational/default.asp.

[33] Armitage G. Human error theory: relevance to nurse management. J NursManag. 2009; 17(2):193-202.

[34] National Coordinating Council for Medication Error Reporting and Prevention (NCC MERP).NCC MERP taxonomy of medication errors. 1998. Available from URL:

http://www.nccmerp. org/pdf/taxo2001-07-31.pdf. Accessed: 2013 July 2.

[35] National Reporting and Learning Service. RLS Help System. Available from URL: https://www.eforms.nrls.nhs.uk/staffreport/help/ALL/eForm_Help.htm. Accessed 2013 July 2.

[36]Keers, R. N., Williams, S. D., Cooke, J., \& Ashcroft, D. M. (2013). Causes of Medication Administration Errors in Hospitals: a Systematic Review of Quantitative and Qualitative Evidence. Drug Safety, 36(11), 1045-1067. 
[37] Weant, K. A., Bailey, A. M., \& Baker, S. N. (2014). Strategies for reducing medication errors in the emergency department. Open Access Emergency Medicine: OAEM, 6, 45-55.

[38] Printed, A., \& Region, S. H. (2011). High Alert Medications - Identification, Double Check and Labeling; \#7311-60-004 Ordering of Medications, 1-9.

[39] Sean Abbot t, H. of C. ient S. ices. (2014). Policy and Procedures on the Administration of Medication, (June), 0-64.

[40] Karapinar C, Arkit F, Terry D. Medication reconciliation: a necessity for continuity of care. Eur J Hosp Pharm Pract. 2011; 17(3):32-3.

[41] Galvin, M., Jago-Byrne, M. C., Fitzsimons, M., \& Grimes, T. (2013). Clinical pharmacist's contribution to medication reconciliation on admission to hospital in Ireland. International Journal of Clinical Pharmacy, 35(1), 14-21.

[42]Bishop, M. A., Cohen, B. A., Billings, L. K., \& Thomas, E. V. (2015). Reducing errors through discharge medication reconciliation by pharmacy services. Am J Health Syst Pharm, 72(17 Suppl 2), S120-6.

[43]Institute for safe medication practice (2013). Independent Double Checks: Undervalued and Misused: Selective Use of This Strategy Can Play an Important Role in Medication from: https://www.ismp.org/newsletters/acutecare/showarticle.aspx?id=51.

[44]Frith, K. H., Anderson, E. F., Tseng, F., \& Fong, E. A. (2012). Nurse staffing is an important strategy to prevent medication error in community hospitals. Nursing Economics, 30(5), 288-294.

[45]Kalisch, B., Landstrom, G., \& Williams, R. (2009). Missed nursing care: Errors of omission. Nursing Outlook, 57(1), 3-9.

[46]Popescu, A., Currey, J., Gert, G., \&Botti, M. (2011, First Quarter). Multifactorial Influences on and deviations from medication administration safety and quality in the acute medical/surgical context. Worldviews on Evidence-Based Nursing: Linking Evidence to Action, pp. 15-24. doi:10.1111/j.1741-6787.2010.00212.x.

[47] Elliott, M., \& Liu, Y. (2010). The nine rights of medication administration: an overview. The British Journal of Nursing, 19(5), 300-305.

[48]Matt Vera, RN. (2012) the 10 Rights of Drug Administration Retrieved from http://nurseslabs.com/10-rs-rights-of-drug-administration/.

[49]Westbrook, J. I. (2010). Association of Interruptions with an Increased Risk and Severity of Medication Administration Errors.Archives of Internal Medicine, 170(8), 683.

[50]Gozdan MJ. (2009). Patient safety: using technology to reduce medication errors. Nursing 2009; 39: 57-58.

[51]Keers, R. N., Williams, S. D., Cooke, J., Walsh, T., \& Ashcroft, D. M. (2014). Impact of interventions designed to reduce medication administration errors in hospitals: A systematic review. Drug Safety, 37(5), 317-332. 
[52] Henneman, P. L., Marquard, J. L., Fisher, D. L., Bleil, J., Walsh, B., Henneman, J. P. Henneman, E. A. (2012). Bar-code Verification. JONA: The Journal of Nursing Administration, 42(12), 562-566.

[53] Elias, B.L., \& Moss, J.A. (2011). Smart pump technology: What we have learned. CIN: Computers, Informatics, Nursing, 29(3), 184-190. doi:10.1097/NCN.0b013e3181fcbe6d.

[54] Langebrake, C., \&Hilgarth, H. (2010). Clinical pharmacists' interventions in a German University Hospital. Pharmacy World and Science, 32(2), 194-199.

[55] Miranda, T. M. M., Petriccione, S., Ferracini, F. T., \& Borges Filho, W. M. (2012). Interventions performed by the clinical pharmacist in the emergency department. Einstein (São Paulo), 10(1), 74-78.

[56]Khalili, H., Farsaei, S., Rezaee, H., \&Dashti-Khavidaki, S. (2011). Role of clinical pharmacists' interventions in detection and prevention of medication errors in a medical ward. International Journal of Clinical Pharmacy, 33(2), 281-284.

[57] Khairat, S., \& Gong, Y. (2010). Understanding effective clinical communication in medical errors. Studies in Health Technology and Informatics, 160(PART 1), 704708.

[58] Nadzam, D. M. (2009). Nurses' Role in Communication and Patient Safety. Journal of Nursing Care Quality, 24(3), 184-188.

[59] Jones, J. H., \&Treiber, L. (2010). When the 5 rights go wrong: Medication errors from the nursing perspective. Journal of Nursing Care Quality, 25(3), 240-247.

[60] Kiekkas, P., Karga, M., Lemonidou, C., Aretha, D., \&Karanikolas, M. (2011). Medication errors in critically ill adults: A review of direct observation evidence. (report). American Journal of Critical Care, (1), 36.

[61] Ashley, E., Back, H., Bissell, H., Bowling, A., Chadwell, S., \& White, S. (2019). Use of Strategy List to Decrease Interruptions during Medication Administration.

[62] Lee, T., \& Lin, F. (2013). The effectiveness of an e-learning program on pediatric medication safety for undergraduate students: A pretest-post-test intervention study. Nurse Education Today, 33, 378-383.

[63] Pauly-O'Neill, S., \& Prion, S. (2013). Using integrated simulation in a nursing program to improve medication administration skills in the pediatric population. Nursing Education Perspectives, 34(3), 148-153. 


\title{
استراتيجيات التمريض للحد من أخطاء الدواء
}

\author{
إيمان عبد الله محمد عبد المطلب ، أماني محمد صفوت \\ قسم التمريض الباطني و الجر احي ، كلية التمريض ، جامعة عين شمس ، مصر
}

نبذه مختصره :تعتبر أخطاء الأدوية في المستشفيات أحد الأسباب الأكثر شيوعًا للضرر غير المقصود للمرضى و هي سبب رئيسي للأخطاء التي تعيب نظام الرعاية الصحية.كما يساهم في الأحداث السلبية

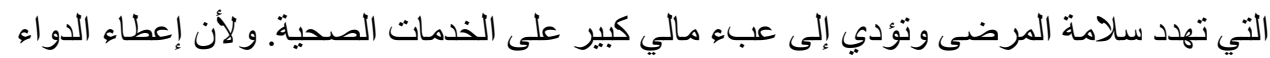

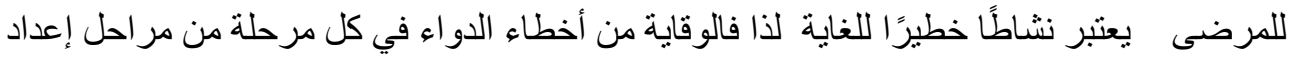

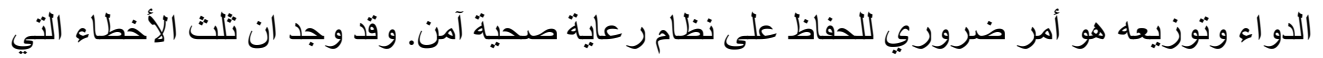

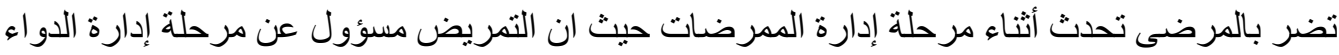

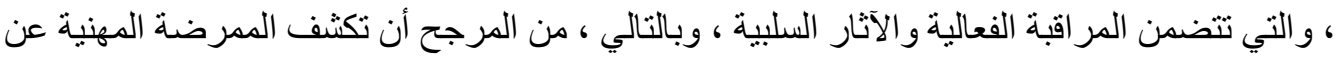

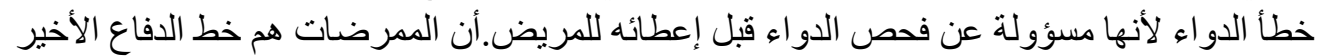

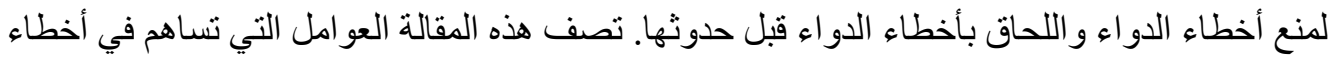

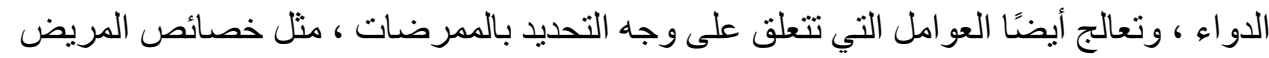

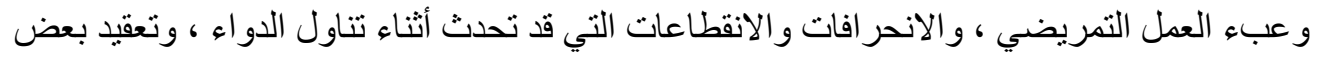
الحسابات و الأدوية ، وفنثل الممرضات في الامتثال للسياسات أو المبادئ التوجيهية. تتضمن المقات المقاله

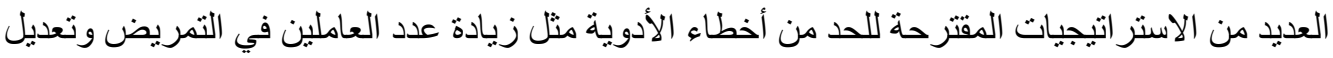

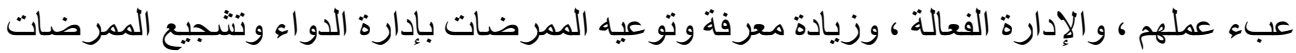

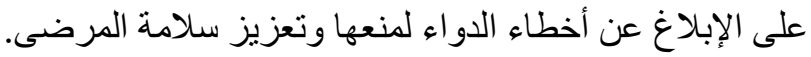

